\title{
Metal İçerikli Hibrid İplik Üretiminde Eş Karıştırma Yönteminin Kullanımı
}

\section{Usage of Co-mingling Process in Production of Metal Hybrid} Yarn

\author{
Abdurrahman Telli $1^{*} \oplus$, İlkan Özkan 1 (1) \\ ${ }^{1}$ Çukurova Üniversitesi Mühendislik Fakültesi Tekstil Mühendisliği Bölümü, Adana, TÜRKIYE \\ Sorumlu Yazar / Corresponding Author*: atelli@cu.edu.tr

\section{$\ddot{\mathbf{O z}}$}

Çalışmada poliamid 6.6 iplikler ile bakır, gümüş ve paslanmaz çelik metal monofilamentler, puntalama makinesinde, eș karıștırma yöntemi ile birleștirilmiştir. Metal filamentler içeren hibrid ipliklerin üretimine hızlı ve düşük maliyetli alternatif bir yöntem oluşturulması amaçlanmıştır. Üretilen hibrid ipliklerin mikroskop görüntüleri alınmıștır. İpliklerde doğrusal yoğunluk tayini, kopma mukavemeti, kopma uzaması ve tüylülük ölçümleri gerçekleştirilmiştir. Metal filament kullanımının iplik kalite değerlerini olumsuz etkilediği görülmüştür. En iyi iplik özellikleri, çelik içerikli hibrid iplikte ölçülmüştür. Gümüş ve özellikle bakır içerikli hibrid iplik üretimlerinde filament kopmaları gerçekleşmiştir. Bu filament kopmalarının, ipliklerin daha sonraki dokuma veya örme gibi işlem adımlarında problem oluşturabilecek düzeyde olduğu görülmüștür. Daha sonraki çalışmalarda puntalama makinesi işlem parametreleri ve metal filament özellikleri üzerinde yapılacak değişiklikler ile iplik özellikleri optimize edilebilecektir.

Anahtar Kelimeler: puntalama, eş karıștırma, metal kompozit iplik, hibrid iplikler

\begin{abstract}
In this study, polyamide 6.6 yarns with copper, silver and stainless steel metal monofilaments were combined in intermingling machine by commingling method. The purpose of this paper is to develop a fast and cost-effective alternative method for production of hybrid yarns containing metal filaments. Microscope images of the produced hybrid yarns were taken. Linear density, breaking force, breaking elongation and hairiness were measured in these yarns. It has been observed that the use of metal filament has a negative effect on yarn quality values. The best yarn properties were obtained from hybrid yarn containing stainless steel. Filament breakage were determined in the production of hybrid yarns containing silver and especially copper metals. It was determined that this filament breakages can be an important problem for subsequent processing steps such as weaving or knitting. In the future studies, the hybrid yarn properties can be optimized by changes on process parameters of intermingling machine and metal filament properties.
\end{abstract}

Keywords: intermingling, co-mingling, metal composite yarn, hybrid yarns 


\section{Giriş}

Teknik tekstiller her geçen gün önem kazanmakta ve pazarı dünya genelinde artış göstermektedir. Teknik tekstiller kavramı içerisindeki teknik iplikler ise, mamullerden arzu edilen teknik performans veya fonksiyonel özelliğin kazandırılabilmesinde büyük önem arz etmektedir. Yenilikçi ürünlerin geliștirilmesinde çeșitli önemli teknik fonksiyonların bir arada istenmesi, aynı zamanda biraz daha estetik ve dekoratif kaygıların ön plana çıkması ile teknik iplikler kompozit bir yapıya bürünmüștür. Farklı özelliklerdeki kesikli liflere çeșitli sistemlerde kompozit iplik formu kazandırılırken, filament malzemelere birleștirme ve bu sırada modifikasyon teknikleri ile istenen yapı kazandırılmaktadır. Yansıtma, UV koruma, anti-bakteriyellik ve elektromanyetik kalkanlama gibi özellikler teknik ipliklerde öne çıkmaktadır. Diğer bilim alanlarındaki gelișmelerin, teknik ipliklerdeki gelişmeleri tetiklediği görülmektedir [1].

İstenilen kullanım alanına göre iki ya da daha fazla sayıda lif veya filamentin bir araya getirilerek kompozit bir yapı kazandırıldığı teknik iplikler, hibrid iplikler olarak isimlendirilmektedirler. Hibrid iplik üretim yöntemlerini özlü (core-spun) iplik üretimi, kaplama (cover) metodu, büküm metodu ve hava jetli sistemler olarak dört ana grupta sınıflandırmak mümkündür [2]. Temel hibrid yapıları; kesikli (matris) ve yüksek mukavemetli kesikli (güçlendirici) lifin bir araya getirilmesiyle, kesikli (matris veya güçlendirici) ve filament (matris veya güçlendirici) lifin bir araya getirilmesiyle, filament (matris) ve filament (güçlendirici) lifin bir araya getirilmesiyle elde edilebilmektedir. Hibrid ipliklerin üretiminde; ring eğirme, open-end rotor eğirme, friksiyon eğirme (Dref), sarmal (wrap) iplikçilik, katlamalı büküm, tow kırma, Twintex filament çekimi, Kemafil teknolojisi, Schappe teknolojisi, paralel sarma, hava jeti ile tekstüre ve puntalama gibi teknikler kullanılabilmektedir $[3,4]$. Puntalama pnömatik bir işlem olup, genellikle filament ipliklerde kullanılan bir ara işlemdir. Hem düz hem de tekstüre ipliklere uygulanabilmektedir. Filamentler arası kohezyon sağlamak için iplikte karıșmıș bölümler olușturulmaktadır [2]. Șekil 1 'de puntalama ișlemi şematize edilmektedir [5]. Literatürde puntalama kalitesini belirleyen etkenler, sıklığı, stabilitesi ve ișlem parametreleri ile ilgili çalıșmalar mevcuttur [6, 7].

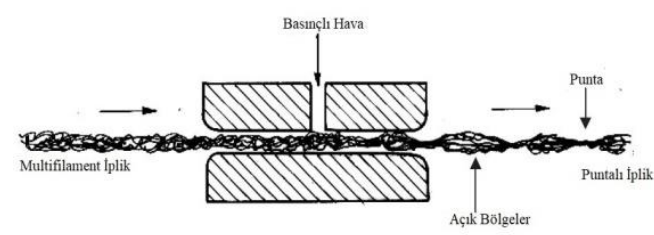

Şekil 1. Puntalama (intermingling) işleminin şematik görünümü [5]

$\mathrm{Bu}$ prensipte puntalama jetleri kullanılmaktadır. Puntalama jeti vasıtasıyla iplik üzerine basınçlı hava uygulanmaktadır ve oluşan hava girdabı iplik boyunca değișen karıșmış ve açık formda bölümlerin oluşturulmasını sağlamaktadır. Puntalama jeti içerisine birden fazla iplik beslenirse bu işleme eş karıştırma (commingling) adı verilmektedir. Oluşan iplikte, iplik üzerindeki periyodik olarak devam eden puntalı kısımlar kompakt yapıda olup, açık bölümler birleștirici yapı olarak görev almaktadır. Çalışılabilen numara aralığının geniş ve üretim maliyetleri düşüktür. Getirdiği optimum teknik özellikler sayesinde, daha önceki çalışmalarda bu işlem için matris filamentler ve yüksek performanslı filamentlerin karıștırıldığı hibrid ipliklerin üretiminde öne çıktığı belirtilmiștir [2, 8].

Literatürde eş karıştırma yönteminde işlem parametrelerinin üretilen iplikler üzerindeki etkisi de incelenmiștir [9]. Bu yöntem ile yapılan çalışmaların büyük çoğunluğu, tekstil takviyeli kompozitlerde kullanılmak üzere üretilen hibrid ipliklerden oluşmaktadır. Bu hibrid ipliklerde cam filamentler ile polyester, nylon ve polipropilen ipliklerin $[10,11,12]$, karbon filamentler ile PEEK (polieter eter keton) ve PPS (polifenilin sülfür) ipliklerin [13, 14], keten ile polilaktikasit liflerinin birleştirildiği [15] görülmektedir. Genellikle hammadde olarak cam ve karbon filamentler güçlendirici, termoplastik esaslı iplikler ise ana yapıyı oluşturmaktadır.

Elektromanyetik kalkanlama, anti-bakteriyel, anti-statiklik/iletkenlik vb. özellikleri ile öne çıkan metal filamentlerinin eş karıştırma yöntemi ile üretilmesine dair literatürde detaylı çalıșma bulunmamaktadır. Bu çalıșmada, daha önceki çalışmalardan farklı olarak, eş karıștırma 
yöntemi ile bakır, gümüș ve paslanmaz çelik metal filamentler ile poliamid 6.6 iplikler birleştirilmiştir. Teknik amaçlı kullanımlar için metal monofilamentler ile poliamid multifilament ipliklerin hızlı ve düşük maliyetli bir șekilde birbirleri üzerinden kaymadan bir arada tutulması amaçlanmıștır. Metal monofilament kullanımı ile kumaş yapısında ortaya çıاkması muhtemel rijitliğin önüne geçmek amacıyla çalışmada çapı küçük metal teller tercih edilmiştir. Böylelikle üretilen ipliklerin teknik yapılara ek olarak hazır giyimde de kullanılabilmesi hedeflenmiștir.

\section{Materyal ve Metot}

Çalışmada 78 denye 68 filament poliamid 6.6 iplikler bakır, gümüş ve paslanmaz çelik metal monofilamentler, Hemaks HMX114 marka puntalama makinesinde, puntalama jeti içerisine birlikte beslenerek eş karıștırma yöntemi ile birleștirilmiștir. Eș karıștırma prensibi ve makine üzerindeki görüntüsü Şekil 2 'de görülmektedir.

İplik üretimlerinde metal filamentler iki naylon iplik arasına merkezlenerek besleme yapılmıștır. Hibrid iplik üretimleri $150 \mathrm{~m} / \mathrm{mn}$ çıkış hızında 5 bar basınç altında gerçekleștirilmiştir. İplik üretiminde işlem parametreleri sabit tutulmuştur. Tablo 1'de çalışmada kullanılan metal filamentlere ait yapısal özellikler sunulmaktadır.

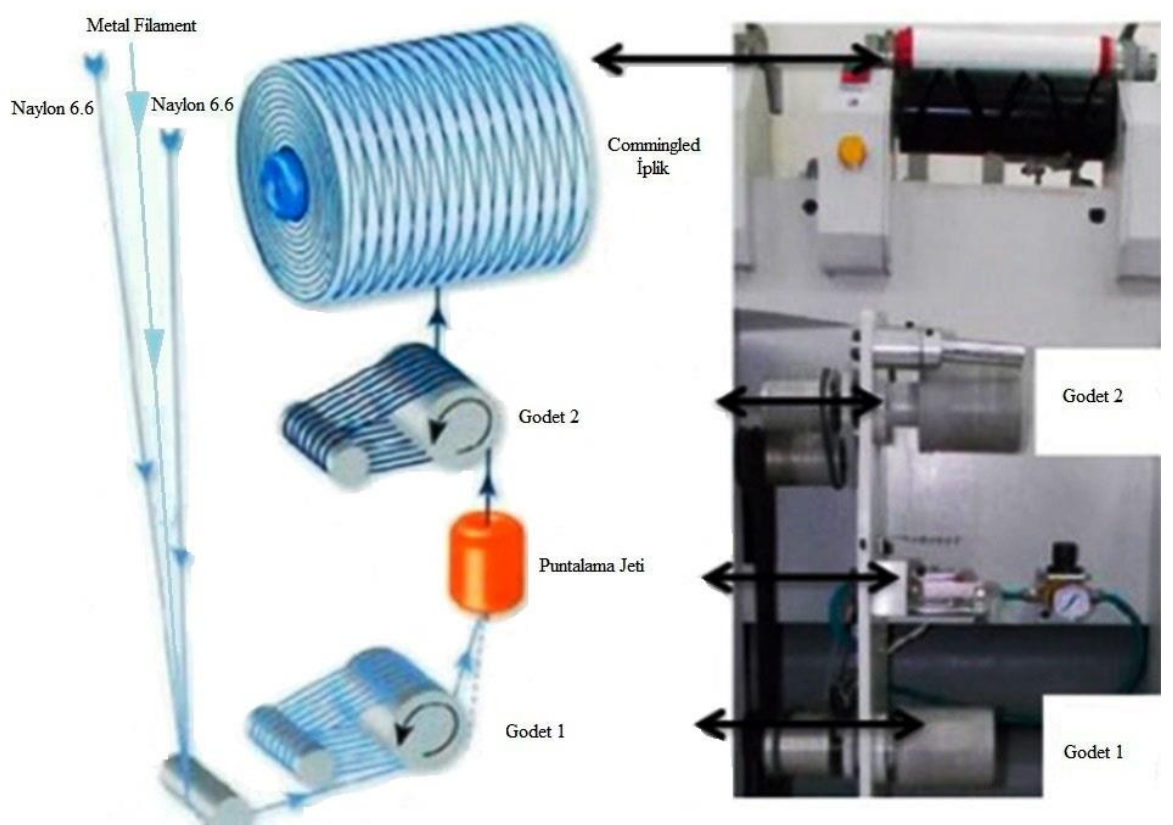

Şekil 2. Puntalama makinesi ve eș karıștırma (commingling) prensibi [7]

Tablo 1. Metal monofilamentlere ait özellikler

\begin{tabular}{|l|l|l|l|}
\hline \multicolumn{1}{|c|}{ Metal Türü } & \multicolumn{1}{|c|}{$\begin{array}{c}\text { Ortalama İncelik } \\
\text { (mm) }\end{array}$} & \multicolumn{1}{c|}{$\begin{array}{c}\text { Ortalama Mukavemet } \\
\text { (cN/tex) }\end{array}$} & $\begin{array}{c}\text { Ortalama Uzama } \\
\text { (\%) }\end{array}$ \\
\hline Paslanmaz Çelik & 0,050 & 11,18 & 34,56 \\
\hline Bakır & 0,050 & 3,24 & 8,18 \\
\hline Gümüş & 0,047 & 5,64 & 18,75 \\
\hline
\end{tabular}

Üretilen dört farklı bileșimdeki hibrid ipliklerde doğrusal yoğunluk tayini, kopma mukavemeti, kopma uzaması ve tüylülük ölçümleri gerçekleștirilmiştir. Ayrıca Novel NSZ 808 
marka stereomikroskop kullanılarak 20x (20 kat) büyütme oranında iplik görüntüleri alınmıştır. İpliklere uygulanan tüm testler, 24 saat süreyle TS EN ISO 139`a göre kondüsyonlanıp standart atmosfer koşullarında $\left(20^{\circ} \mathrm{C} \pm 2\right.$ sicaklık, $\% 65 \pm 4$ bağıl nem) gerçekleștirilmiștir. Doğrusal yoğunluk tayini TS 244 EN ISO 2060 standardına göre çile metodu ile gerçekleștirilmiștir. İplik kopma mukavemeti ve uzaması ölçümleri TS 245 EN ISO 2062 standardına göre Titan Universal marka mukavemet cihazında $250 \mathrm{~mm}$ ölçüm aralığı esas alınarak yapılmıştır. $250 \mathrm{~mm} / \mathrm{mn}$ ölçüm hızı ile her bir iplikten 20 adet ölçüm alınmıștır. Sonuçlar özgül mukavemet (cN/tex) ve kopma uzaması (\%) olarak değerlendirilmiștir. Üretilen hibrid iplikler metal filamentler içerdikleri için kapasitif ölçüm prensibi ile çalışan cihazlarda değerlendirilememektedir. Bu nedenle tüylülük ölçümleri optoelektronik ışık bariyer sistemi kullanan "Zweigle G 567" test cihazında gerçekleştirilmiştir. Numune iplik aynı anda 12 ışık bariyeri ile ölçülmekte ve bu sayede farklı uzunluktaki lifler aynı anda sayılabilmektedir. İplik yüzeyinden çıkan 1, 2, 3, 4, 6, 8, 10, 12 ve $15 \mathrm{~mm}$ uzunluğundaki tüyleri ölçüp sayan ayrı

ayrı optik okuyucular mevcuttur. İplik testleri, $50 \mathrm{~m} / \mathrm{mn}$ hızda 100m'lik 5'er adet ölçüm alınarak gerçekleştirilmiştir. Tüylülük sonuçlarının değerlendirilmesinde "S3" ve "S12" sonuçları esas alınmıştır. İplik kopma mukavemeti, kopma uzaması ve tüylülük (S3) sonuçları SPSS paket programında \%95 güven aralığında istatistiki olarak incelenmiştir.

\section{Bulgular}

Calışmada üretilen dört farklı tipteki hibrid ipliklerin kompozisyonları Tablo 2'de görülmektedir. Şekil 3'de ise üretilen dört farklı ipliğe ait mikroskop görüntüleri yer almaktadır.

Tablo 2. Dört farklı tipteki ipliklerin kompozisyonları

\begin{tabular}{|c|c|c|}
\hline $\begin{array}{c}\text { Iplik } \\
\text { Kodu }\end{array}$ & $\begin{array}{c}\text { Kat } \\
\text { Adedi }\end{array}$ & İplik Kompozisyonu \\
\hline NN & 2 & $\begin{array}{c}\text { Poliamid 6.6 + } \\
\text { Poliamid 6.6 }\end{array}$ \\
\hline NCN & 3 & $\begin{array}{c}\text { Poliamid 6.6 + } \\
\text { Çelik + Poliamid 6.6 }\end{array}$ \\
\hline NBN & 3 & $\begin{array}{c}\text { Poliamid 6.6 + } \\
\text { Bakır + Poliamid 6.6 }\end{array}$ \\
\hline NGN & 3 & $\begin{array}{c}\text { Poliamid 6.6 + } \\
\text { Gümüş + Poliamid 6.6 }\end{array}$ \\
\hline
\end{tabular}

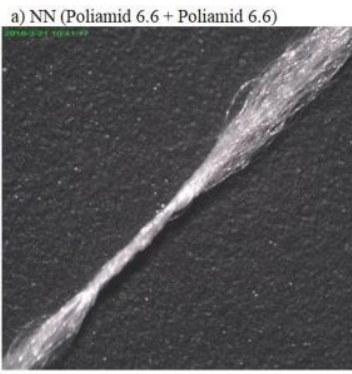

b) NCN (Poliamid 6.6 + Celik + Poliamid 6.6)
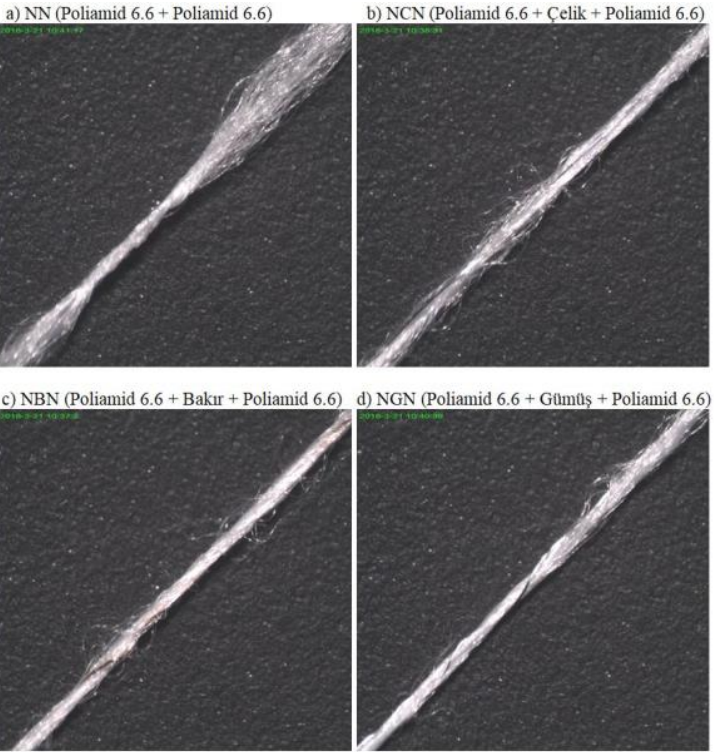

Şekil 3. Hibrid ipliklerin 20x (20 kat) büyütme oranında mikroskobik görüntüleri

Çalışmada kullanılan ipliklerin ilgili standartlara uygun kalite-kontrol testleri yapılmıștır. $\mathrm{Bu}$ testler neticesinde ulașılan iplik doğrusal yoğunluğu (tex), kopma mukavemeti (cN/tex), kopma uzaması (\%), tüylülük "S3" (adet) ve 
DEU FMD 22(64), 1-9, 2020

"S12" (adet) test sonuçlarının ortalama değerleri Tablo 3'de verilmektedir.

Tablo 3. Dört farklı tipteki ipliklerin ortalama test sonuçları

\begin{tabular}{|c|c|c|c|c|c|}
\hline İplik Kodu & $\begin{array}{c}\text { Doğrusal } \\
\text { yoğunluk (tex) }\end{array}$ & $\begin{array}{c}\text { Kopma Mukavemeti } \\
\text { (cN/tex) }\end{array}$ & $\begin{array}{c}\text { Kopma } \\
\text { Uzamasi (\%) }\end{array}$ & $\begin{array}{c}\text { Tüylülük } \\
\text { (S12) }\end{array}$ & $\begin{array}{c}\text { Tüylülük } \\
\text { (S3) }\end{array}$ \\
\hline NN & 17,4 & 36,38 & 28,54 & 81 & 2 \\
\hline NCN & 24,7 & 21,82 & 23,48 & 2388 & 32 \\
\hline NBN & 34 & 17,95 & 26,39 & 2223 & 133 \\
\hline NGN & 29 & 19,16 & 24,95 & 3665 & 90 \\
\hline
\end{tabular}

Tablo 3'deki nihai katlı iplik doğrusal yoğunlukları incelendiğinde, iki kat poliamid 6.6'nın kullanıldığı NN kodlu ipliğe göre üç kat olan NCN, NBN ve NGN kodlu iplikler beklenildiği gibi yüksek değerler almıştır. Ancak metal monofilament çapları benzer seçilmesine rağmen (Tablo 1) üç kat hibrid ipliklerde farklı şekilde sonuçlar alınmıștır. En yüksek değer bakır içerikli NBN kodlu iplikte görülürken, en düșük doğrusal yoğunluk ise NCN kodlu çelik içerikli hibrid iplikte ölçülmüştür. Üçüncü yapı olarak ipliğe katılan metaller arasındaki malzeme yoğunlukları farkları, bu durumu oluşturmuştur. Üç ana iplik kalite özelliği olan kopma mukavemeti, kopma uzaması ve tüylülük (S3) sonuçları ise Şekil 4'de görülmektedir.

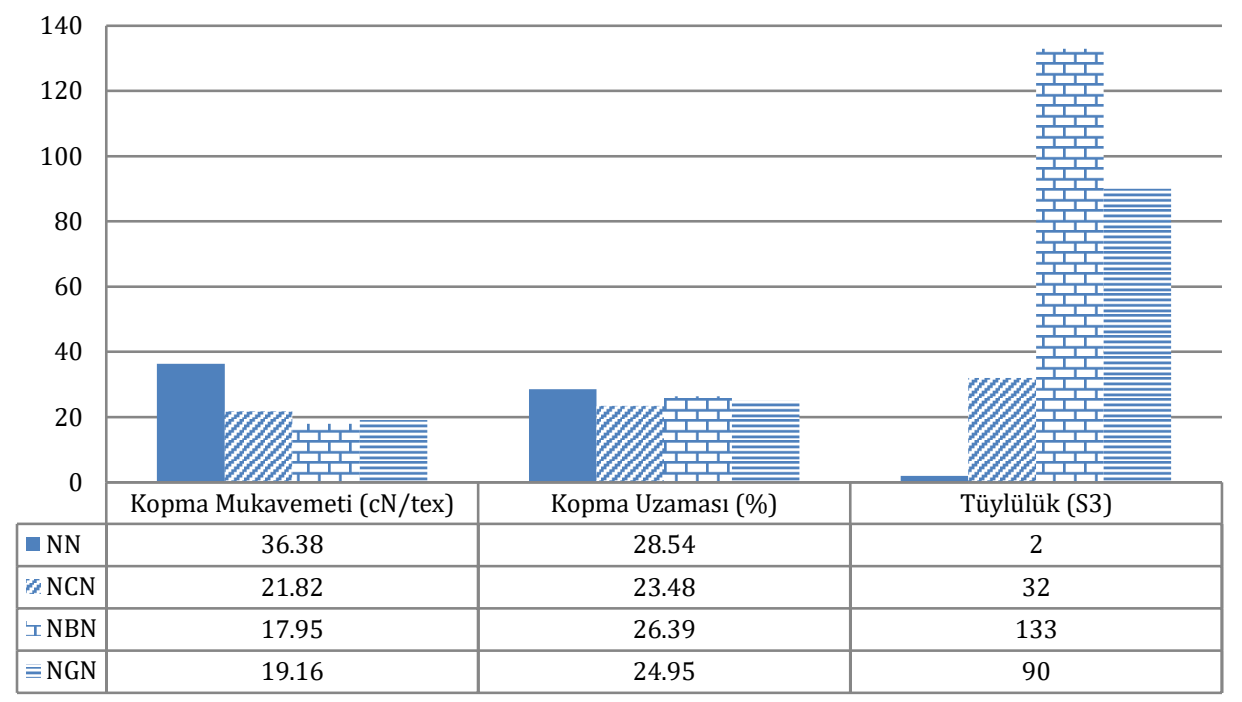

Şekil 4. Kopma mukavemeti, kopma uzaması ve tüylülük (S3) sonuçları

İplikler için gerçekleştirilen varyans analizine göre ipliklerin kopma mukavemetleri [F (3, 79) $=260,879$; $\mathrm{p}=0,0006]$, kopma uzamaları [F $(3,79)=6,221 ; p=0,001]$ ve tüylülük sonuçları arasındaki fark $[F(3,19)=39,683 ; p=0,001]$ önemli bulunmuştur. Dört farklı iplik ölçüm sonuçları arasında varyanslarının eşit olup olmadığı Levene homojenlik testi ile incelenmiştir. Gruplar arasındaki varyanslar kopma mukavemeti $(\mathrm{p}=0,0002<0,05)$, kopma uzaması $\quad(p=0,0001<0,05) \quad$ ve tüylülük $(p=0,0001<0,05)$ sonuçlarında eșit olmadığı için çoklu karşılaştırma testi “Tamhane T2" yöntemi kullanılmıştır. Çoklu karşılaştırma test sonuçlarından elde edilen istatistiksel anlamlılık (p) değerleri Tablo 4'de verilmektedir. 
DEU FMD 22(64), 1-9, 2020

Tablo 4. Çoklu karşılaştırma test sonuçlarından elde edilen istatistiksel anlamlılık (p) değerleri

\begin{tabular}{|c|c|c|c|c|}
\hline & NN & NCN & NBN & NGN \\
\hline NN & ---- & $\begin{array}{c}\mathrm{cN} / \mathrm{tex}=\mathbf{0 , 0 0 0 6}^{*} \\
\%=\mathbf{0 , 0 1 8}^{*} \\
\mathrm{~S} 3=\mathbf{0 , 0 0 5}^{*}\end{array}$ & $\begin{array}{c}\text { cN/tex }=\mathbf{0 , 0 0 0 1}^{*} \\
\%=0,640 \\
\mathrm{~S} 3=\mathbf{0 , 0 0 8}^{*}\end{array}$ & $\begin{array}{c}\mathrm{cN} / \text { tex }=\mathbf{0 , 0 0 0 9} * \\
\%=0,149 \\
\mathrm{~S} 3=\mathbf{0 , 0 0 3} *\end{array}$ \\
\hline NCN & $\begin{array}{c}\mathrm{cN} / \mathrm{tex}=\mathbf{0 , 0 0 0 6}{ }^{*} \\
\%=\mathbf{0 , 0 1 8} \\
\mathrm{S} 3=\mathbf{0 , 0 0 5}\end{array}$ & ----- & $\begin{array}{c}\mathrm{cN} / \mathrm{tex}=\mathbf{0 , 0 0 0 1} \\
\%=\mathbf{0 , 0 0 7} \\
\% 3=\mathbf{0 , 0 1 7}\end{array}$ & $\begin{array}{c}\mathrm{cN} / \text { tex }=\mathbf{0 , 0 0 0 1} * \\
\%=0,524 \\
\mathrm{~S} 3=\mathbf{0 , 0 0 7} *\end{array}$ \\
\hline NBN & $\begin{array}{c}\text { cN/tex }=\mathbf{0 , 0 0 0 1}^{*} \\
\%=0,640 \\
\mathrm{~S} 3=\mathbf{0 , 0 0 8}^{*}\end{array}$ & $\begin{array}{c}\mathrm{cN} / \operatorname{tex}=\mathbf{0 , 0 0 0 1} \\
\%=\mathbf{0 , 0 0 7} \\
\% \\
\mathrm{~S} 3=\mathbf{0 , 0 1 7} *\end{array}$ & ---- & $\begin{array}{c}c \mathrm{cN} / \text { tex }=\mathbf{0 , 0 0 2} * \\
\%=0,321 \\
\mathrm{~S} 3=0,296\end{array}$ \\
\hline NGN & $\begin{array}{c}\mathrm{cN} / \text { tex }=\mathbf{0 , 0 0 0 9} * \\
\%=0,149 \\
\mathrm{~S} 3=\mathbf{0 , 0 0 3}^{*}\end{array}$ & $\begin{array}{c}\mathrm{cN} / \operatorname{tex}=\mathbf{0 , 0 0 0 1} \\
\%=0,524 \\
\mathrm{~S} 3=\mathbf{0 , 0 0 7}\end{array}$ & $\begin{array}{c}c \mathrm{cN} / \mathrm{tex}=\mathbf{0 , 0 0 2} * \\
\%=0,321 \\
\mathrm{~S} 3=0,296\end{array}$ & ---- \\
\hline
\end{tabular}

Kopma mukavemeti sonuçları incelendiğinde, en yüksek kopma mukavemeti değeri NN kodlu iplikte görülmüştür (Tablo 3, Şekil 4). Hibrid ipliklerde, NN kodlu ipliğe göre daha düşük mukavemetler elde edilmiştir. İplikler arasındaki fark istatistiksel olarak önemli bulunmuștur (Tablo 4). Hibrid ipliklerde metal malzeme kullanımının mukavemeti olumsuz yönde etkilediği görülmektedir. Bu sonuçlar metal monofilamentlerin kopmasiyla açıllanabilir. Hibrid iplik üretimleri esnasında eș karıștırma için gerekli hava basıncının etkisiyle belirsiz aralıklarla filamentlerde kopmalar gerçekleșmiștir. $\mathrm{Bu}$ kopmalar malzemelerin rijitliği ile ilişkilidir. Tablo 1'deki benzer ortalama incelik değerlerine sahip metal uzama özellikleri incelendiğinde, en rijit yapıya bakır filamentlerin sahip olduğu görülmektedir. En fazla kopma, en rijit yapıdaki bakır filamentlerde gerçekleşmiștir. Daha sonra sırasıyla gümüş ve çelik filamentler gelmektedir. Kopmalar, metal filamentlerin mukavemete katkı yapmasını engellemiștir. İpliğe direkt olarak yansıyarak kopma mukavemetini olumsuz anlamda etkilemiştir. Hibrid iplikler arasında en düşük kopma mukavemeti değeri, NBN kodlu bakır içerikli iplikte ölçülmüştür. En yüksek değer ise NCN kodlu çelik içerikli iplikte bulunmuştur. Aralarındaki farklar istatistiksel olarak önemli seviyededir (Tablo 4).

Tablo 3 ve Șekil 4'deki kopma uzaması sonuçları incelendiğinde ise, mukavemetteki kadar olmasa da NN kodlu ipliğe göre, hibrid ipliklerde metal malzeme kullanımının uzamayı olumsuz etkilediği görülmektedir. Benzer şekilde, farklı üretim tekniklerinin kullanıldığı daha önceki çalışmalarda hibrid iplik yapısında metal filament kullanımının kopma mukavemeti ve uzamasını olumsuz etkilediği raporlanmıştır. Özlü iplik üretim tekniği kullanan Bedeloğlu vd. (2012) ve Telli vd. (2017) benzer sonuçlar elde etmiștir [16, 17]. Örtlek vd. (2003) ise farklı büküm teknikleri kullandıkları çalıșmalarında bakır filamentler ile üretimde, iplik kopma mukavemeti ve uzamasında düșüș kaydetmişlerdir [18]. İplik kopma mukavemeti ve uzamasındaki bu düşüşlere çözüm olarak literatürde çeşitli öneriler getirilmiştir. $\mathrm{Bu}$ çalışmalarda, özlü iplik üretim tekniğinde, öz oranı arttıkça kesitteki lif sayısı ve kesikli liflerden yararlanma oranı azaldığ mukavemet ve uzamanın olumsuz etkilendiği belirtilmektedir. Liflerin merkezdeki öz üzerine homojen ve düzgün etki yapma eğiliminin artırılması için mantoda kullanılan kesikli lif oranının artırılması veya farklı liflerin tercih edilmesi önerilmektedir [16, 17, 19, 20]. Büküm teknikleri ile üretimlerde ise büküm miktarı değiştirilerek iplik özelliklerinin geliştirilebileceği belirtilmektedir $[18,20]$. İçi boș iğ üretim tekniği ile üretimde ise kaplamada kullanılan ipliğin, hibrid ipliğin mukavemet ve uzamasında ana faktör olduğu kaydedilmiștir. Ayrıca metal filamentin çapı artırılarak iplik değerlerinin düzeltilebileceği vurgulanmıștır [21].

Hibrid iplikler arasında en yüksek kopma uzaması değeri, NBN kodlu bakır içerikli iplikte ölçülmüştür. En düşük değer ise NCN kodlu çelik içerikli iplikte bulunmuștur. Kopma uzamalarında NBN kodlu bakır içerikli $(p=0,640)$ ve NGN kodlu gümüş içerikli $(\mathrm{p}=0,149)$ hibrid ipliklerin, NN kodlu iplik ile arasındaki fark istatistiksel olarak önemsiz seviyededir. Sadece çelik içerikli iplik ile aralarındaki fark önemli seviyede bulunmuştur $\left(p=0,018^{*}\right)$. Diğerlerine göre filament 
kopmalarının çok daha az yaşandı̆̆ çelik içerikli hibrid ipliklerde, metal malzemenin iplik yapısına daha fazla katkı yapabilmesi hibrid ipliği daha kompakt ve kırılgan bir yapıya büründürmüştür. Gümüş ve özellikle bakır içerikli ipliklerde ise kopmalar nedeniyle metaller kaydığı için uzama yükünü hibrid iplik yapısındaki poliamid 6.6 multifilamentler iplikler üstlenmiș, uzama karakteristiği iplikte ön plana çıkmıştır. Literatürde de, metal filament içeren hibrid ipliklerde kopma mukavemeti ve uzaması açısından yapıdaki bileşenlerin birleşik etkisinin önemi vurgulanmıștır. Metal filamentin kopmasıyla, hibrid iplik özelliklerinin yapıdaki diğer bileşenin karakteristiğine göre şekil alacağı belirtilmektedir [21,22].

Üretimler esnasında gümüş ve özellikle bakır içerikli hibrid iplik üretimlerinde eș karıștırma için gerekli hava basıncının etkisiyle belirsiz aralıklarda gerçekleșen metal filament kopmaları, ipliğe direkt olarak yansıyarak iplik gövdesinde düzgünsüzlüklere sebebiyet vermiștir. $\mathrm{Bu}$ kopmalar nedeniyle olușan düzgünsüzlük dokunarak ve gözle sübjektif olarak nitelendirilebilmektedir. Ancak düzgünsüzlük cihazları kapasitif prensipte çalıştığından metal içerik nedeniyle ölçüm alınamamaktadır. Bahsedilen metal kopmalarının verdiği düzgünsüzlüğü objektif olarak ifade etmek için optoelektronik ișı bariyer sistemi kullanan Zweigle tüylülük cihazı kullanılmıștır. Çünkü filament iplik yapılarında kesiksiz olduklarından dolayı, iplik yüzeyinden rahatsız edici lifler çıkmamaktadır. Çalışmada hibrid ipliği oluşturan tüm iplikler filamentlerden olușmaktadır. Metal filamentlerin pürüzsüz yüzey yapısı da göz önünde bulundurulduğunda, tüm hibrid ipliklerde çok düşük miktarda tüylülük beklenir. Ancak üretimler sırasında metal filamentlerin önemli miktarda kopması burada farklı sonuçlar ortaya çıkarmıştır. Dört farklı tipteki ipliklerin detaylı tüylülük ortalama test değerleri Tablo 5'de yer almaktadır.

İplik tüylülüğü, bu cihaza göre birim uzunluk boyunca iplik yüzeyinden dışarı doğru çıkan liflerin sayısı veya lif uzunluğudur. İplik yüzeyinden çıkan $3 \mathrm{~mm}$ ve üzerindeki uzunluklardaki lif sayılarının toplamını ifade eden "S3", $3 \mathrm{~mm}$ altındaki sarkan lif uzunluklarının rahatsız edici olmadığ düşüncesinden hareketle belirlenmiștir. Normalde cihazdan alınan tüylülük değerleri kesikli liflerden oluşan iplikler hakkında bilgi vermektedir. Kesiksiz liflerde rahatsız edici seviyede bir tüylülük oluşmaz. Tablo 5'deki "S3" değerleri incelendiğinde, beklenildiği gibi NN kodlu iplikte çok düşük (2 adet) tüylülük değeri elde edilmiştir.

Tablo 5. Dört farklı tipteki ipliklerin detaylı tüylülük ortalama test değerleri

\begin{tabular}{|c|c|c|c|c|c|c|c|c|c|c|c|}
\hline $\begin{array}{c}\text { Iplik } \\
\text { Kodu }\end{array}$ & $\begin{array}{c}1 \\
\mathrm{~mm}\end{array}$ & $\begin{array}{c}2 \\
\mathrm{~mm}\end{array}$ & $\mathbf{S 1 2}$ & $\begin{array}{c}3 \\
\mathrm{~mm}\end{array}$ & $\begin{array}{c}4 \\
\mathrm{~mm}\end{array}$ & $\begin{array}{c}6 \\
\mathrm{~mm}\end{array}$ & $\begin{array}{c}8 \\
\mathrm{~mm}\end{array}$ & $\begin{array}{c}10 \\
\mathrm{~mm}\end{array}$ & $\begin{array}{c}12 \\
\mathrm{~mm}\end{array}$ & $\begin{array}{c}15 \\
\mathrm{~mm}\end{array}$ & $\mathbf{S 3}$ \\
\hline NN & 73 & 8 & $\mathbf{8 1}$ & 2 & 0 & 0 & 0 & 0 & 0 & 0 & $\mathbf{2}$ \\
\hline NCN & 2176 & 212 & $\mathbf{2 3 8 8}$ & 28 & 4 & 0 & 0 & 0 & 0 & 0 & $\mathbf{3 2}$ \\
\hline NBN & 1810 & 413 & $\mathbf{2 2 2 3}$ & 83 & 29 & 7 & 4 & 7 & 2 & 2 & $\mathbf{1 3 3}$ \\
\hline NGN & 3127 & 539 & $\mathbf{3 6 6 5}$ & 67 & 18 & 4 & 1 & 0 & 0 & 0 & $\mathbf{9 0}$ \\
\hline
\end{tabular}

Metal içerikli hibrid ipliklerde de NN kodlu iplik ile benzer "S3" değerlerine ulaşılması beklenir. Ancak üretimler sırasında metal filamentlerin önemli miktarda kırıldığı bakır ve gümüș içerikli hibrid ipliklerde yüksek "S3" değerleri görülmüştür.

Sektörde kullanılan kesiksiz standart bir ipliğe göre yüksek olmayan bu "S3" değerlerinin "mm" olarak dağılımları, Tablo 5'deki verilerden detaylı olarak incelenerek NN kodlu iplik ile kıyaslandığında, söz konusu filament kopmalarının etkisi bu şekilde kendini göstermektedir. NCN kodlu çelik içerikli $\left(\mathrm{p}=0,005^{*}\right)$, NBN kodlu bakır içerikli $\left(\mathrm{p}=0,008^{*}\right)$ ve NGN kodlu gümüș içerikli $\left(p=0,003^{*}\right)$ hibrid ipliklerin, NN kodlu iplik ile arasındaki fark istatistiksel olarak önemli seviyededir (Tablo 4). Hibrid iplik üretimleri sırasında en fazla kopma, metal uzama özellikleri nedeniyle en rijit yapıya sahip bakır filamentlerde gerçekleșmiștir. Daha sonra sırasıyla gümüș ve çelik filamentler gelmektedir. Bu nedenle hibrid 
DEU FMD 22(64), 1-9, 2020

iplikler arasında en yüksek "S3" değeri 133 adet ile bakır içerikli iplikte görülürken, daha sonra sırasıyla gümüş (90 adet) ve çelik (32 adet) içerikli ipliklerde ölçülmüştür. En düşük değer çelik içerikli hibrid ipliklerde bulunmuștur. NCN kodlu ipliğin NBN kodlu bakır içerikli $\left(\mathrm{p}=0,017^{*}\right)$ ve NGN kodlu gümüş içerikli $\left(\mathrm{p}=0,007^{*}\right)$ hibrid iplikler ile arasındaki fark istatistiksel olarak önemli seviyelerde bulunmuştur (Tablo 4). Çelikten farklı olarak gümüş içerikli iplikte $6 \mathrm{~mm}$ ve $8 \mathrm{~mm}$ uzunluğundaki lifler mevcut iken, bakır içerikli iplikte $10 \mathrm{~mm}, 12 \mathrm{~mm}$ ve $15 \mathrm{~mm}$ uzunluğunda dahi lifler ölçülmüştür (Tablo 5). Açık bir şekilde görülebilen bu lif kopmaları, metallerin doğası gereği iplikleri rahatsız edici bir yapıya ulaştırmaktadır. NBN ve NGN kodlu iplikler arasındaki fark ise istatistiksel olarak önemsiz seviyededir $(\mathrm{p}=0,296)$.

Sübjektif değerlendirmede ise, gümüş içerikli hibrid ipliğin bakıra göre bir miktar daha rahatsız ettiğini söylemek mümkündür. $\mathrm{Bu}$ durum ise Tablo 4'deki "S12" değerleri incelendiğinde açıklanabilir. "S12", 1 ve $2 \mathrm{~mm}$ uzunluğundaki tüylerin toplam değeridir. Sektörde rahatsız edici olmayan tüylülük olarak bilinen bu değer, metalin sert karakteri nedeniyle burada tutum açısından daha farklı bir anlam kazanmaktadır. Gümüş içerikli hibrid ipliğin diğer ipliklere nazaran daha yüksek değer aldığı net bir şekilde görülmektedir.

Metal filament özellikleri ile alınan tüm sonuçlar birlikte düşünüldüğünde, bu çalışmada elde edilen kopma mukavemeti ve kopma uzaması ölçüm değerleri, dokuma ve örme sektöründe kullanım açısından her üç hibrid iplik için de yeterli olarak görünmektedir. Benzer ortalama inceliğe sahip metal monofilamentler için tercih edilen makine parametrelerinde, gümüș ve özellikle bakır içerikli hibrid ipliklerde filament kopmaları gerçekleşmiștir. Çelik içerikli iplikte, bakır ve gümüş içerikli ipliklere nazaran daha verimli bir eș karıștırma gerçekleștirilmiștir. Monofilament mukavemet ve uzaması bakır ve gümüșe göre yüksek olan çelik içerikli hibrid ipliklerin üretimlerinde kayda değer bir problem ile karşılaşılmamıştır. Bunun yanı sıra diğer iki hibrid ipliğe göre daha iyi iplik sonuçları elde edilmiștir.

Bakır ve gümüs içerikli hibrid iplik üretimlerinde hem lif kopmalarının azaltılması hem de iplik özelliklerinin geliștirilmesi amacıyla bu iki tip için metal monofilament çaplarının artırılmasının bir çözüm sunabileceği düşünülmektedir. Ancak metal çapının artmasıyla mukavemet, uzama, düzgünsüzlük ve tüylülük değerleri olumlu etkilenirken, sertlik değerlerinin rahatsız edici seviyeye gelebileceğini gözden kaçırmamak gerekmektedir. Literatürde metal çap artışlarının sertlik değerlerini artıracağı belirtilmektedir [21].

Hava basıncı, iplik gerilimi ve geçiș hızı vb. parametre değișikliklerinin, elde edilecek iplik özellikleri üzerinde etkili olduğu daha önceki çalışmalarda vurgulanmıştır [7]. Bu çalışmada kullanılan eş karıştırma tekniğiyle bakır ve gümüș içerikli hibrid iplik üretiminde, daha kalın monofilament tercihi ve puntalama makinesi işlem parametreleri üzerinde yapılacak değişiklikler ile iplik özelliklerinin bir miktar daha iyileștirilebileceği açıktır. Ayrıca metal filamentlerin iplik yapısında görünmesinin istenmediği durumlarda, filament sayısı ve doğrusal yoğunluğu daha fazla ve daha hacimli taşıyıcı filamentler kullanmak çözüm getirebilecektir. $\mathrm{Bu}$ şekilde metal filamentler içeren hibrid ipliklerin üretimine hızlı ve düşük maliyetli alternatif bir yöntem oluşacaktır.

\section{Sonuç}

Bu çalışmada daha önceki çalışmalardan farklı olarak, eș karıștırma yöntemi ile metal monofilament içerikli hibrid iplik üretimleri gerçekleştirilmiştir. Çeşitli teknik fonksiyonları ile öne çıkan metal filamentlerin kullanıldığı eş karıștırma tekniği ile üretimde, en iyi iplik kalite özelliklerini çelik içerikli hibrid iplikler vermiștir. Gümüş ve özellikle bakır içerikli hibrid iplik üretimlerinde filament kopmaları gerçekleşmiştir. $\mathrm{Bu}$ filament kopmalarının, ipliklerin daha sonraki dokuma veya örme gibi isslem adımlarında problem olusturabilecek düzeyde olduğu görülmüştür. Ayrıca metallerin doğası gereği ipliklerin tutumunda ve görüntüsünde rahatsız edici bir yapı oluşmaktadır. Bu alanda daha sonra yapılacak çalıșmalarda, eș karıștırma prensibi ile puntalama makinesinde üretimlerde hava basıncı, iplik gerilimi ve geçiş hızı vb. parametre değişiklikleri, farklı malzeme kullanımları, metal çapı ve filament özellikleri gibi değişkenlerin etkisini incelemek anlamlı olacaktır. Ayrıca bu prensipte üretilen ipliklerin 
DEU FMD 22(64), 1-9, 2020

yüzey haline getirilerek, diğer yöntemlere göre, elektromanyetik kalkanlama, anti-bakteriyel, anti-statiklik/iletkenlik vb. özellikleri açısından incelenmesi kendine özgü ilginç sonuçlar ortaya çıkarabilecektir.

\section{Teşekkür}

Bu çalıșma Çukurova Üniversitesi BAP Birimi tarafindan desteklenmiștir (Proje Kodu: FBA-2018-10062).

\section{Kaynakça}

[1] Çukul, D. (2013). Teknik İpliklerde Son Yllardaki Gelişmelere Örnekler. Tekstil ve Mühendis, 20(91).

[2] Bursa Tekstil \& Konfeksiyon Ar-Ge Merkezi. (2015). Butekom Akademi-Tekstilde Özel Konular, Cilt 4Kompozit İplik Üretimi ve İplik Kaplama Eğitim Kitapçığı. $50 \mathrm{~s}$.

[3] Kaplan, M. (2016). Termoplastik Kompozitler için Hibrit İplik Üretimi. Tekstil ve Mühendis, 23(101)

[4] Alagirusamy, R., \& Das, A. (Eds.). (2010). Technical textile yarns. Elsevier.

[5] Alagirusamy, R., \& Ogale, V. (2004). Commingled and air jet-textured hybrid yarns for thermoplastic composites. Journal of Industrial Textiles, 33(4), 223-243.

[6] Özkan, İ., \& Baykal, P. D. (2012). Puntalama İşleminde Üretim Parametrelerinin ve Filament Özelliklerinin Punta Kalıcılığına Etkisi. Tekstil ve Mühendis, 19(87).

[7] Duru Baykal, P., \& Özkan, İ. (2013). The effects of intermingling process parameters and number of filaments on intermingled yarn properties. The Journal of The Textile Institute, 104(12), 12921302.

[8] Kannan, T. G., Wu, C. M., \& Cheng, K. B. (2012). Effect of different knitted structure on the mechanical properties and damage behavior of Flax/PLA (Poly Lactic acid) double covered uncommingled yarn composites. Composites Part B: Engineering, 43(7), 2836-2842.

[9] Mankodi, H., \& Patel, P. (2010). Study the effect of commingling parameters on glass/polypropylene hybrid yarns properties. Autex Research Journal, $9(3)$.

[10] Alagirusamy, R., Ogale, V., Vaidya, A., \& Subbarao, P. M. V. (2005). Effect of jet design on commingling of glass/nylon filaments. Journal of Thermoplastic Composite Materials, 18(3), 255-268.

[11] Alagirusamy, R., \& Ogale, V. (2005). Development and characterization of GF/PET, GF/Nylon, and GF/PP commingled yarns for thermoplastic composites. Journal of Thermoplastic Composite Materials, 18(3), 269-285.

[12] Long, A. C., Wilks, C. E., \& Rudd, C. D. (2001). Experimental characterisation of the consolidation of a commingled glass/polypropylene composite. Composites science and technology, 61(11), 15911603.

[13] Ye, L., Friedrich, K., Kästel, J., \& Mai, Y. W. (1995). Consolidation of unidirectional CF/PEEK composites from commingled yarn prepreg. Composites science and technology, 54(4), 349-358.
[14] Schäfer, J., Stolyarov, O., Ali, R., Greb, C., Seide, G., \& Gries, T. (2016). Process-structure relationship of carbon/polyphenylene sulfide commingled hybrid yarns used for thermoplastic composites. Journal of Industrial Textiles, 45(6), 1661-1673.

[15] Kannan, T. G., Wu, C. M., \& Cheng, K. B. (2012). Effect of different knitted structure on the mechanical properties and damage behavior of Flax/PLA (Poly Lactic acid) double covered uncommingled yarn composites. Composites Part B: Engineering, 43(7), 2836-2842.

[16] Bedeloglu, A., Sunter, N., Yildirim, B., Bozkurt, Y., 2012, Bending and tensile properties of cotton/metal wire complex yarns produced for electromagnetic shielding and conductivity applications, The Journal of The Textile Institute, 103:12, 1304-1311.

[17] Telli, A., Dașan, Y., Babaarslan, O. and Karaduman, S., (2017). Usage of Core and Dual-Core Yarns Containing Tungsten for Electromagnetic Shielding. Advance Research in Textile Engineering. 2(1): 1013.

[18] Örtlek, H. G., Çalıșkan, C.., \& Kurban, R. (2013). A comparative study on the physical properties of hybrid yarns containing copper wire. 2013 (Volume: 20), 89.

[19] Babaarslan, O., 2001, Method of Producing a Polyester/Viscose Core-Spun Yarn Containing Spandex Using a Modified Ring Spinning Frame, Textile Research Journal, 71:4, 367-371.

[20] Lou, C. W. (2005). Process of complex core spun yarn containing a metal wire. Textile Research Journal, 75(6), 466-473.

[21] Çeven, E. K., \& Aytaş, H. (2016). Investigation of Tensile and Stiffness Properties of Composite Yarns with Different Parameters. Fibres \& Textiles in Eastern Europe, (4 (118)), 51-58.

[22] Perumalraj, R., \& Dasaradan, B. S. (2010). Tensile properties of copper core yarn. Journal of Reinforced Plastics and Composites, 29(11), 16881701. 